\title{
"MAS ISSO É PORQUE AS PESSOAS NÃO SABEM O QUE É O POLE DANCE": CONTRIBUIÇÕES DA AVALIAÇÃO PARA A ANÁLISE DISCURSIVA DE ESTIGMAS
}

\section{"BUT THAT'S BECAUSE PEOPLE DON'T KNOW WHAT POLE DANCING IS": CONTRIBUTIONS OF EVALUATION TO THE DISCURSIVE ANALYSIS OF STIGMAS}

\author{
Lorena Araujo Alves* \\ Adriana Nogueira Accioly Nóbrega**
}

\section{RESUMO}

Neste artigo, investigamos uma interação entre praticantes do pole dance, com foco na reação e na resistência relacionadas à recorrente construção de estigmas sobre a atividade. Inserida na área da Linguística Aplicada Contemporânea, a pesquisa volta-se à observação dos mecanismos discursivos avaliativos negociados pelas interlocutoras e às contribuições destes para a ressignificação da atividade que praticam. A análise microdiscursiva fundamenta-se no sistema de avaliatividade, integrante da Linguística Sistêmico-Funcional, quando percebemos quais estigmas são problematizados nos discursos das participantes, a partir de avaliações realizadas, principalmente, nas esferas do afeto e do julgamento. O paradigma qualitativo orienta a metodologia do estudo, com o corpus gerado pela gravação de uma conversa entre a primeira autora e sua professora da modalidade. Nossos entendimentos sugerem que as participantes concebem o pole dance como uma prática libertadora, construindo um discurso que o ressignifica positivamente e que resiste a visões hegemônicas conservadoras, as quais estigmatizam a atividade e a consideram uma prática vulgar e desviante da normalidade.

Palavras-chave: avaliação; estigmas; pole dance.

\section{ABSTRACT}

In this article, we investigate an interaction between pole dancing practitioners, focusing on the reaction and the resistance related to the recurrent construction of stigmas about the activity. Inserted in the area of Contemporary Applied Linguistics, the research is centered

\footnotetext{
* Pontifícia Universidade Católica do Rio de Janeiro PUC-RJ, Rio de Janeiro, RJ, Brasil. lorena allves15@hotmail.com

Orcid: https://orcid.org/0000-0002-7015-7770

** Pontifícia Universidade Católica do Rio de Janeiro PUC-RJ, Rio de Janeiro, RJ, Brasil. adriananobrega@puc-rio.br Orcid: https://orcid.org/0000-0002-0194-0120
} 
on the observation of the discursive evaluative mechanisms negotiated by the interlocutors and their contributions to the reframing of the activity they practice. The microdiscursive analysis is based on the appraisal theory, imbedded in Systemic-Functional Linguistics. Evaluations produced mainly in the domains of affect and judgment are highlighted in order to foreground the stigmas problematized in participants' discourses. The methodology is oriented by the qualitative paradigm and the corpus was generated in a recorded conversation between the first author and her pole dancing teacher. Our understandings suggest that participants conceive pole dancing as a liberating practice, creating a discourse that reframes it positively and that resists against conservative hegemonic views, such as the ones which stigmatize the activity and consider it a vulgar and deviant practice.

Keywords: evaluation; stigmas; pole dancing.

\section{CONSIDERAÇÕES INICIAIS}

O pole dance é uma atividade que vem se tornando cada vez mais presente na contemporaneidade, sendo exercida por diversas pessoas, desde crianças a praticantes mais velhos, incluindo homens e mulheres. No desejo de fazer uma atividade física mais dinâmica e estimulante, muitos o procuram por reconhecerem nele uma maneira de trabalhar o seu corpo e a sua autoestima de modo desafiador, e ao mesmo tempo encorajador, pela prática mista de ginástica com dança - uma modalidade que se diferencia das opções mais tradicionais de exercício físico. Há todo um significado positivo e de importância para os seus praticantes, que veem nele, dentre outras qualidades, a capacidade de libertação do corpo e da mente, bem como de evolução das suas potencialidades (HOLLAND, 2010; ALLEN, 2011).

Por outro lado, praticantes de pole dance podem sofrer muitos preconceitos por parte de um pensamento conservador, que o avalia negativamente, o reprova e o marginaliza. Segundo Gonçalves (2017), é extremamente comum pole dancers, independente do estilo ou da vertente que sigam, serem alvos de julgamentos negativos, comentários machistas, misóginos e sexistas, além de posturas castradoras ao exporem a sua prática, como no caso de postagens em redes sociais. Os comentários são de todos os níveis, desde censuras à vestimenta, aos movimentos e aos tipos de danças expostos nas fotos e vídeos, até atitudes invasivas de envio de nudes e de oferecimento de relações sexuais.

Podemos encontrar investigações sobre o pole dance em diferentes campos do saber, como, por exemplo, na Antropologia (LEAL E SILVA, 2014; GONÇALVES, 2017), Filosofia (ALLEN, 2011), Psicologia (WHITEHEAD; KURZ, 2009; FERREIRA, 2015), Educação Física (SANTOS, 2018), nas Artes (OLIVEIRA, 2016) e no Direito (MEEPOS, 2012), Na área dos Estudos da Linguagem, na qual esta pesquisa se insere, acreditamos que ainda há poucos estudos sobre a temática, 
principalmente em um abordagem crítica. Nesse cenário, como analistas críticas do discurso, temos como motivação principal impulsionar a discussão sobre estigmas sociodiscursivamente criados em torno do universo do pole dance, pois julgamos ser necessário denunciar e problematizar tais significados negativos no âmbito de investigações conduzidas na área da Linguística Aplicada Contemporânea (MOITA LOPES et. al., 2006, 2013; PENNYCOOK, 2006), à qual nos alinhamos.

Além disso, como pole dancer, Lorena, primeira autora deste artigo, já passou por situações estigmatizantes como as descritas acima, trazendo para o presente estudo uma motivação pessoal, intimamente ligada aos interesses da segunda autora, Adriana, de investigar criticamente o uso da linguagem em diversas práticas sociais. Acreditamos, portanto, que possamos colaborar para o processo de reflexão sobre o pole dance na área dos estudos do discurso, na intenção de corromper a frequente visão negativa acerca da modalidade e de propor "novas formas de percepção e de organização da experiência não comprometidas com lógicas e sentidos históricos viciados" (FABRÍCIO, 2006, p. 52). Além disso, sugerimos que nossas discussões sejam uma relevante contribuição para o acervo bibliográfico sobre essa atividade física e artística no contexto acadêmico brasileiro.

Para podermos criar inteligibilidades (MOITA LOPES, 2006) sobre o tema que ora abordamos, temos o objetivo geral de refletir sobre os discursos hegemônicos ${ }^{1}$ (FAIRCLOUGH, 1997, 2001) que se referem ao pole dance, problematizando os sentidos que o estigmatizam (GOFFMAN, [1963] 1988, [1964] 1998) e seus praticantes, a fim de coconstruir entendimentos sobre esta comunidade. Mais especificamente, nossos objetivos centram-se em trazermos as vozes de duas praticantes, a saber, a primeira autora deste estudo e sua professora, e observar como se dá a resistência ${ }^{2}$ aos estigmas e a ressignificação do pole dance em seus discursos, a partir da análise dos mecanismos de avaliação.

Fundamentamos a arquitetura teórica na área da Linguística Aplicada Contemporânea (MOITA LOPES et. al. 2006, 2013; RAJAGOPALAN, 2003), em especial nas teorizações sobre estigma (GOFFMAN, [1963] 1988, [1964] 1998), em interface com os estudos de avaliação propostos pela Linguística SistêmicoFuncional (HALLIDAY; MATHIESSEN, 2014; MARTIN; WHITE, 2005;

1. Segundo Fairclough (1997, p. 80), o conceito de hegemonia "implica o desenvolvimento em vários domínios da sociedade civil [...] - de práticas que naturalizam relações e ideologias específicas e que são, na sua maioria, práticas discursivas".

2. Neste estudo, nos baseamos na noção de "resistência" de forma abrangente, ou seja, a partir de seu sentido dicionarizado: (i) não aceitação, negação ou recusa, geralmente voltadas a um determinado poder ou força superior; (ii) forma de manter-se firme e não sucumbir; (iii) ação em defesa própria (MICHAELIS, 2020). 
THOMPSON; ALBA-JUEZ, 2014) para a análise dos afetos e dos julgamentos presentes no discurso avaliativo que re-constrói os sentidos sobre estigmas. Tal interface confere o caráter socioconstrucionista (MOITA LOPES, 2002) da pesquisa, que visa a discutir o uso da linguagem em uma prática específica, qual seja, o discurso sobre a atividade do pole dance, assim como objetiva investigar os significados criados ao longo da interação.

\section{UM BREVE PANORAMA SOBRE O POLE DANCE}

Definir o que seja o pole dance torna-se uma tarefa complexa, uma vez que ele pode ser conceituado de diversas maneiras por seus praticantes e entusiastas, variando de descrições mais técnicas - a execução de acrobacias em uma barra vertical - a mais metafóricas, por exemplo, entendendo-o como uma forma de libertação (FERREIRA, 2015; GONÇALVES, 2017). Tomando de início a tradução livre do próprio termo, vemos que o pole dance envolve o dançar, isto é, ele é um tipo de dança (dance) que faz uso de uma barra vertical (pole), de inox ou de ferro, em sua composição coreográfica. A barra é utilizada para a realização de inúmeros movimentos de danças, como os do ballet, da dança contemporânea, das danças urbanas etc.; os livremente criados; e os ginásticos - de ginástica olímpica/artística, rítmica e do contorcionismo. Os movimentos podem ser feitos em modos estático e giratório na própria barra, bem como fora dela (ESPAÇO ALFA, 2014).

A ginástica é um elemento constitutivo do pole dance e, portanto, além de dança, ele também é considerado um esporte, muitas vezes procurado justamente para atuar como exercício físico (SANTOS, 2018). Referimo-nos à/ao praticante como atleta-artista porque é exatamente isso que a/o pole dancer é. Em nosso entendimento, o qual é compartilhado por muitos membros de sua comunidade, a/o pole dancer é, ao mesmo tempo, dançarina/o, performer e ginasta em sua prática e em apresentações, que precisam ser encaradas como uma expressão artística. Como pontua Gonçalves (2017), é possível que, por "embaralhar os limites de arte e esporte, de entretenimento e atletismo, transformando uma atividade de alta exigência física em algo divertido e prazeroso" (GONÇALVES, 2017, p. 11), o pole dance atraia muitas pessoas.

Existem muitos segmentos dentro do pole dance, todos mesclando a ginástica com a dança. O que varia são os diferentes níveis e formas com que esses elementos serão trabalhados no que é tido como suas principais vertentes - os grandes panos de fundo de onde outras subcategorias possam se originar - o Sexy Pole, o Pole Sport ou Acro Pole e o Pole Art (GONÇALVES, 2017). Um ponto a ser destacado relaciona-se 
ao desenvolvimento do pole dance como uma atividade principalmente feminina, muito provavelmente devido aos contextos iniciais em que foi praticado, onde as mulheres eram as que realizavam suas performances, a exemplo dos clubes de striptease (stripclubs) e cabarés. Até os dias de hoje, em todos os seus segmentos, o público feminino é maioria.

A fim de contextualizarmos o pole dance como uma prática social, onde a linguagem exerce papel predominante para a construção dos sentidos a serem aqui analisados, apresentamos, a seguir, os princípios da Linguística Aplicada Contemporânea e a sua relação com questões que tangem o contexto do pole dance.

\section{A PESQUISA SOBRE O POLE DANCE: QUESTÕES PERTINENTES À LINGUÍSTICA APLICADA CONTEMPORÂNEA}

A Linguística Aplicada Contemporânea (doravante, LAC) se configura como uma área de estudos situada no âmbito das ciências sociais pós-modernas. Com o propósito de "criar inteligibilidades sobre os problemas sociais" (MOITA LOPES, 2006, p. 14), a LAC busca entendê-los a partir da investigação crítica do uso da linguagem que permeia os mais diversos contextos. Nesta perspectiva, surgem novos interesses de pesquisa e, com isso, criam-se interfaces com outros campos de estudo, a exemplo das temáticas de desigualdades, raça, gênero e sexualidade, identidades, emoções, dentre outras (BUTLER, 1988, 1990; MIGNOLO, 2000; hooks, 1982, 1984; COLLINS, 2017; REZENDE; COELHO, 2010). Ocorre um direcionamento do olhar contemporâneo para os indivíduos periféricos, os que são marginalizados e encarados como inferiores e subalternos (FABRÍCIO, 2006), tornando-se de grande interesse para a LAC a criação de espaços para a inclusão de visões alternativas que propiciem o entendimento do mundo contemporâneo. As novas reflexões acerca da complexidade da vida social, realizadas na esfera teórico-metodológica da LAC, são possíveis devido à sua natureza transdisciplinar, indisciplinar e mestiça (MOITA LOPES et. al., 2006), características fundacionais em seu desenvolvimento. Em suas contribuições para a área, Pennycook (2006) acrescenta ainda a qualidade transgressiva da LAC, recusando demarcações disciplinares e propondo atravessamentos e cruzamentos, já que concebe os campos de estudo como não estáticos, mas sim como "domínios dinâmicos do conhecimento" (PENNYCOOK, 2006, p. 72).

Em consonância com a visão contemporânea de Linguística Aplicada, entendemos seus princípios como altamente pertinentes para a investigação de questões que perpassam a prática do pole dance. Com base em sua abordagem 
crítica de linguagem, é nosso intuito gerar entendimentos sobre o tema desta pesquisa, a partir da problematização dos discursos que circulam acerca do pole dance, principalmente os que o estigmatizam e suas/seus praticantes por meio de julgamentos negativos e preconceituosos. Nesse sentido, adotamos a noção de estigma proposta pelo antropólogo Erving Goffman, para quem o estigmatizado é "o indivíduo que está inabilitado para a aceitação social plena" (GOFFMAN, [1963] 1988, p. 4), uma vez que emite sobre si, de forma voluntária ou involuntária, uma imagem social tida como negativa.

Ainda segundo o autor, a estigmatização ocorre nas interações sociais e configura-se como a rotulação de um indivíduo, a partir de um atributo que o distingue como diferente e que o fará ser reconhecido como "uma pessoa estragada e diminuída. Tal característica é um estigma, especialmente quando o seu efeito de descrédito é muito grande - algumas vezes ele também é considerado um defeito, uma fraqueza, uma desvantagem." (GOFFMAN, [1963] 1988, p. 6). Não se pode ignorar a presença das relações de poder e de assimetria no processo de classificação do sujeito portador do atributo diferencial, que é estigmatizado por outro indivíduo considerado como normal, segundo os padrões normativos da sociedade (BIAR, 2012).

Norteadas pelas considerações de Goffman ([1963] 1988, [1964] 1998), observamos, nos macrodiscursos hegemônicos e estigmatizantes, o julgamento do pole dance como uma prática de vulgarização do corpo feminino, destinada a satisfazer ao público masculino, de exploração da sexualidade de forma indevida, dentre outras ${ }^{3}$. Ao realizar uma atividade marginalizada, a praticante é, consequentemente, também marginalizada, visto que não se pode dissociar a pessoa de suas práticas sociais, da vida que vive. Dessa maneira, a pole dancer está sujeita a rotulações diretas por exercer a modalidade, assim como a definições depreciativas presentes no senso comum conservador - "coisa de puta" e a alcunha de "vulgar", dentre outras - possíveis de serem encontradas nas redes sociais, em conversas cotidianas e na mídia de forma geral.

É coerente pensar, então, que há uma dupla estigmatização das pole dancers. Uma primeira que ocorre anteriormente a qualquer fator, uma vez que, por se tratarem de mulheres, já sofrem com ações machistas, misóginas e sexistas. Somando-se a isto, o segundo estigma volta-se ao fato de serem pole dancers, vítimas em potencial de todas as condutas cerceadoras comentadas até o momento. Portanto, notamos

3. O público masculino praticante do pole dance também sofre estigmatizações, com julgamentos similares e/ou de outras magnitudes, porém as questões relacionadas a tal público não se inserem no escopo deste estudo. 
que as críticas recebidas pelas mulheres, no fundo, refletem os posicionamentos estereotipados em relação ao "papel da mulher" na sociedade, o que ela deve ou não fazer, como deve comportar-se, dentre outros aspectos controladores da liberdade e da agentividade femininas. Todas essas considerações são por nós concebidas como pontos políticos e ideológicos significativos e, por isso, socialmente relevantes.

Como praticante do pole dance, Lorena faz parte do grupo estigmatizado, adquirindo um status negativo no discurso hegemônico e cujas vozes são as marginalizadas. Todavia, são vozes que buscam resistir contra os discursos cristalizados, dado que, como ainda afirma Gonçalves (2017), há um conflito entre a imagem social externa do que seja o pole dance e a percepção de quem está "de dentro" - de como ele é vivido e compreendido pelas praticantes. É a partir da experiência das participantes desta pesquisa que tomamos como necessário desafiar a ideia fundamentada em estereótipos a respeito do pole dance, como um ato de esclarecimento e de resistência sobre a sua prática.

Inspiradas pela LAC, almejamos estabelecer uma agenda anti-hegemônica, ao criarmos inteligibilidades sobre a vida contemporânea com os que estão à margem (MOITA LOPES, 2006), isto é, trazendo para o centro as visões e os posicionamentos de pole dancers. Na interação que aqui focamos, ao avaliarem e serem avaliadas, as participantes lidam com a estigmatização do pole dance. Percebemos que os momentos avaliativos presentes no discurso de Lorena e de Marina ${ }^{4}$, sua professora, possuem extrema relevância para que possamos compreender como os recursos avaliativos contribuem para um discurso de resistência aos estigmas que atravessam a atividade.

\section{O PAPEL DA AVALIAÇÃO NA ANÁLISE DO DISCURSO DE RESISTÊNCIA AOS ESTIGMAS ACERCA DO POLE DANCE}

A avaliação é um potencial recurso para a criação de sentidos em práticas discursivas e interacionais. É por meio dela que falantes/escritores expressam suas opiniões, ilustrando seus sistemas de valores e das comunidades nas quais se inserem, além de serem elementos de construção e de manutenção das relações entre falante/escritor e ouvinte/leitor, atuando como organizadores de discursos (HUNSTON; THOMPSON, 2000; THOMPSON, ALBA-JUEZ, 2014). Tal visão de avaliação coaduna-se com a noção de discurso como elemento coparticipativo e interacionalmente construído (MOITA LOPES, 2002), conforme proposto

4. Nome fictício. 
pela LAC, uma vez que os participantes de dado encontro social constroem colaborativamente seus posicionamentos diante dos eventos avaliados. Desse modo, Lorena e Marina avaliam a prática do pole dance em seu contexto particular de atuação e fazem emergir seus sistemas de crenças e de valores quanto à modalidade em si, sempre em referência ao contexto macrossocial hegemônico. É no entrecruzar dos contextos que podemos observar uma possível resistência e ressignificação dos sentidos estigmatizantes, tomando como base uma perspectiva de linguagem em uso, quando sentidos são interacionalmente criados em situações específicas.

Diante disso, os fatores contextuais são fundamentais para a análise da linguagem avaliativa, em uma relação dialógica, onde os elementos macro e micro sociais, ou seja, tudo o que estiver circundando o falante/escritor e ouvinte/ leitor em seu uso da linguagem (THOMPSON, ALBA-JUEZ, 2014) é levado em consideração para que possamos contemplar o potencial avaliativo na construção de significados. Entretanto, para que seja possível olhar a prática discursiva avaliativa com as lentes propostas, faz-se necessário adotarmos uma abordagem de linguagem que tome por pressuposto os seus contextos de produção e de recepção, em uma perspectiva sociossemiótica, conforme o proposto pela Linguística SistêmicoFuncional (LSF) (HALLIDAY; MATTHIESSEN, 2014).

Em possível interface com a LAC, a LSF analisa a linguagem a partir de suas situações de uso, como nos estudos desenvolvidos no âmbito da LAC, que tendem a "focalizar a linguagem como prática social e observá-la em uso, imbricada em ampla amalgamação de fatores contextuais" (FABRÍCIO, 2006, p. 48). Nossa proposta caracteriza-se, então, pela recusa de fronteiras entre áreas do saber, havendo cruzamentos teóricos e metodológicos compatíveis, conforme o caráter transdisciplinar, indisciplinar, mestiço e transgressivo da LAC (MOITA LOPES, 2006; PENNYCOOK, 2006). Além disso, é importante pontuar que a perspectiva da LSF extrapola o caráter linguístico, debruçando-se não só sobre as questões de língua e de linguagem, mas também sobre as políticas, antropológicas e ideológicas, que emergem nos e dos discursos, levando a caminhos em direção à transdisciplinaridade (VIAN JR., 2013).

Nesse sentido, a LSF fundamentará a análise micro dos discursos voltados às questões de estigma e, particularmente, nos interessa observar a negociação da avaliação enfocando o seu sistema de avaliatividade (MARTIN, 2000; MARTIN, WHITE, 2005), que lida com a linguagem da avaliação e volta-se: (i) à expressão de atitudes negociadas em um texto; (ii) à intensidade dos sentimentos envolvidos; e (iii) aos modos como valores são atribuídos e leitores alinhados (MARTIN; ROSE, 2007). De acordo com Nóbrega (2009), o sistema de avaliatividade pode ser definido 
como um arcabouço teórico-metodológico, inserido no âmbito das avaliações interpessoais, no nível da semântica-discursiva, em que as avaliações são negociadas ao longo das interações, segundo aspectos particulares a cada contexto interacional. Além disso, conforme afirma Vian Jr. (2010, p. 25), o sistema de avaliatividade referese "a todo o potencial que a língua oferece para realizarmos significados avaliativos" e constitui-se por três subsistemas: a Atitude ${ }^{5}$, o Engajamento e a Gradação. Em nossas análises, observamos os significados atitudinais ${ }^{6}$ - os quais representam os posicionamentos e as opiniões sobre a entidade que está sob avaliação - nos seus três campos semânticos: Afeto, Julgamento e Apreciação.

A avaliação por Afeto diz respeito à expressão das emoções, à forma como nos sentimos em relação às pessoas, aos objetos e aos acontecimentos avaliados, relacionando-se ao afeto de in/felicidade, de in/satisfação e de in/segurança. O Julgamento é a institucionalização do afeto no campo da ética e da moralidade, configurando-se como a avaliação que fazemos do comportamento de pessoas. Os julgamentos podem ser feitos na esfera da estima social, envolvendo crítica e admiração, sem implicações legais, no que tangem à normalidade, à capacidade e à tenacidade. Já na esfera da sanção social, os julgamentos abarcam elogios e condenações, muitas vezes com implicações legais, referindo-se à veracidade e à propriedade. Por sua vez, a Apreciação se define como o valor que atribuímos às coisas, aos objetos, aos fenômenos e também às pessoas no que toca à sua estética, ou seja, é a institucionalização do afeto no campo estético. A apreciação pode estar relacionada às categorias de reação, de composição e de valoração. As avaliações podem ser realizadas de forma explícita ou implícita, positiva ou negativa (MARTIN; ROSE, 2007).

Reforçamos que a linha de separação entre os campos é extremamente tênue, com barreiras praticamente inexistentes (MARTIN; ROSE, 2007), e ressaltamos que esta categorização é proposta somente para fins de análise discursiva, sendo o Afeto o domínio que permeia os outros dois campos, que o institucionalizam de acordo com seus propósitos. Por vezes, existe, ainda, certa ambiguidade no que diz respeito à identificação do domínio avaliativo. Para Martin e White (2005), idealizadores do quadro teórico da Avaliatividade, existem casos onde não é evidente a fronteira que separa o Julgamento da Apreciação, ou seja, a separação entre a avaliação de

5. Usamos iniciais maiúsculas para a redação do nome dos subsistemas da Avaliatividade, a fim de evitarmos confusão no uso dos termos em sua forma mais rotineira.

6. Propomos um recorte na análise de nosso corpus, enfatizando o subsistema da Atitude sem que, com isso, não reconheçamos a importância dos subsistemas do Engajamento e da Gradação para uma melhor compreensão dos mecanismos avaliativos nos discursos aqui investigados. Recomendamos a leitura de Martin e White (2005) e Marin e Rose (2007) para a descrição dos referidos subsistemas. 
comportamento humano e a de qualidade de um objeto/ entidade irá depender de fatores contextuais para que a análise seja proposta.

\section{CAMINHOS METODOLÓGICOS E ANÁLISE DOS DADOS}

Os dados gerados ${ }^{7}$ para a análise proposta provêm de uma entrevista conversacional semi-estruturada (MISHLER, 1986) entre Lorena e outra pole dancer, Marina, professora e sócia-proprietária da Living Pole Dances, no Rio de Janeiro, onde Lorena realiza a modalidade há quatro anos e tem a função de monitora nas aulas de Marina. A professora pratica a atividade há 8 anos e, apesar de ser formada em arquitetura, não exerce a profissão, tendo decidido focar profundamente nas práticas profissionais relacionadas à sua vivência no pole dance: professora e empresáriaadministradora da escola. Além disso, dedica-se à carreira de atleta profissional, participando de competições, dentro e fora do país, conquistando diversos títulos.

A interação teve o objetivo de melhor conhecermos a relação da professora com o contexto do pole dance, o que a atividade significa para ela, além de saber a sua opinião em relação a alguns tópicos que perpassam esse mundo. Tratou-se, assim, de um encontro entre pares, trazendo as perspectivas de quem está "de dentro". A conversa foi gravada em áudio, com duração de 11 minutos e teve os seguintes pontos, previamente organizados: Como você começou a fazer pole dance e por quê? $\mathrm{O}$ que é o pole dance para você? $\mathrm{O}$ que ele representa em sua vida?; $\mathrm{O}$ que você acha sobre a relação pole dance e preconceito? Ressaltamos que as perguntas serviram apenas como um simples roteiro para a interação, não havendo, em momento algum, nossa pretensão de que as mesmas servissem como um questionário ou que fossem literalmente respondidas. Os dados foram transcritos de acordo com as convenções propostas por Sacks, Schegloff e Jefferson (1974), com contribuições de Loder e Jung (2009), conforme apresentado na tabela que inserimos ao final do artigo (cf. Anexo).

Alinhadas ao paradigma metodológico qualitativo, que concebe a pesquisa como uma atividade situada e que visa à interpretação e não à mensuração dos dados (DENZIN, LINCOLN, 2006), analisamos, como dito anteriormente, alguns momentos da interação com o objetivo de investigar como as escolhas

7. Esta pesquisa está fundamentada "no respeito pela dignidade humana e na proteção devida aos participantes das pesquisas científicas envolvendo seres humanos", em consonância com a Resolução n 510 (Conselho Nacional de Saúde, 2016). Ressaltamos que o estudo possui parecer da Câmara de Ética em Pesquisa da Pontifícia Universidade Católica do Rio de Janeiro (PUC-Rio) e que a geração dos dados ocorreu apenas depois da assinatura do Termo de Consentimento Livre e Esclarecido (TCLE) por Marina.

8. Nome fictício. 
léxico-gramaticais avaliativas são negociadas entre as interlocutoras e como tais avaliações contribuem para a reflexão crítica e consequente resistência a lógicas preconceituosas e estigmatizantes que envolvem o pole dance.

O início de nossas análises centra-se no momento em que Lorena pergunta à Marina, de forma mais geral, sobre como ela vê a atividade, em que ela consiste e o que representa em sua vida. A professora responde, então, que o pole dance é basicamente toda a sua vida, uma vez que vive dele para lazer e trabalho e para criação de laços de amizade. É nesse contexto interacional que, logo após, a professora desenvolve a sua perspectiva de como o enxerga, conforme apresentado no excerto 1.

Excerto 1

\begin{tabular}{|c|c|}
\hline Marina & $\begin{array}{l}\text { show e: e o que que é a atividade de pole dance } \\
\text { assim (.) ○ que [que é essa atividade] pra você? } \\
\text { [por definição?] }\end{array}$ \\
\hline $\begin{array}{l}\text { Marina } \\
\text { Lorena }\end{array}$ & =é $\quad[$ por definição?] $=$ \\
\hline $\begin{array}{l}\text { Lorena } \\
\text { Marina }\end{array}$ & =é a >atividade de pole dance< por definição são \\
\hline Lorena & $\begin{array}{l}\text { acrobacias em uma barra vertical } \\
\text { [uhum] }\end{array}$ \\
\hline Marina & $\begin{array}{l}\text { [por definição] (.) mas se você quiser sair da } \\
\text { definição ela é uma dança (.) ao mesmo tempo ela } \\
\text { é um esporte ao mesmo tempo ela é uma [arte]= }\end{array}$ \\
\hline Lorena & [sim] \\
\hline Marina & $\begin{array}{l}\text { =uma forma de expressão (.) e >pra muita gente é } \\
\text { uma libertação porque: : existe muita a questão de } \\
\text { você (.) aprender a lidar com o seu próprio corpo } \\
\text { (.) e é um ambiente que você tem que lidar (.) } \\
\text { basicamente (.) o dia [inteiro] }\end{array}$ \\
\hline Lorena & - $\quad$ [uhum] \\
\hline Marina & $\begin{array}{l}\text { =seminua de top e short porque a gente precisa do } \\
\text { do contato da pele com a barra >senão você não } \\
\text { consegue praticar< (.) então é é é por definição } \\
\text { pra mim ele é uma libertação também pra voê ê } \\
\text { aprender a se olhar e a ver o que você é capaz de } \\
\text { fazer (.) estando seminua numa sala que tem um } \\
\text { espelho de piso a teto }\end{array}$ \\
\hline $\begin{array}{l}\text { Lorena } \\
\text { Marina }\end{array}$ & uhum \\
\hline Marina & $\begin{array}{l}\text { e tentando de alguma } f c \\
\text { que você vê (.) e sim }\end{array}$ \\
\hline
\end{tabular}

O discurso de Marina nos remete às suas avaliações positivas da atividade. Notamos que há um mecanismo discursivo avaliativo que evidencia o seu posicionamento, a partir de instâncias de afeto institucionalizadas em julgamentos positivos de estima social, principalmente os de capacidade. Esta manobra discursiva desloca a avaliação para o que o pole dance proporciona, o que ele acarreta a suas praticantes, especialmente em seus comportamentos, ou seja, o que elas podem ou não realizar ou sentir. Nesse sentido, ela avalia a modalidade de forma mais 
indireta, colaborativamente com sua interlocutora, que ratifica suas opiniões (linhas 26, 32 e 40). De acordo com o que vemos no excerto 1, é possível dizer que a professora parece propor um contradiscurso aos estigmas sofridos pelo pole dance, mencionados na discussão apresentada ao longo do artigo. Por conseguinte, ela traz um olhar dos "de dentro" (GONÇALVES, 2017), construído com alto grau de envolvimento pelo uso inclusivo/coletivo do pronome pessoal "você", relacionado a si mesma, à Lorena e às outras pole dancers. Em nosso entendimento, há toda uma negociação de suas avaliações, pois ao incluir indiretamente Lorena em sua fala, a professora a convida a coavaliar os eventos. Este aspecto reflete o proposto por Martin e Rose (2007), que afirmam que a linguagem da avaliação lida com a expressão de atitudes negociadas em um texto e aos modos como valores são atribuídos e leitores alinhados.

O posicionamento da professora é construído a partir da linha 18, quando menciona a conjugação de elementos esportivos e artísticos para descrever o pole dance. Mais adiante, Marina constrói uma definição mais metafórica, ao dizer que para muita gente (linha 27), e para ela inclusive (linha 36), o pole dance é uma libertação. Tal libertação pode ser entendida como uma força motriz para comportamentos positivos, calcados na estima social por capacidade. Os julgamentos das potencialidades do pole dance acabam por avaliar o papel que ele tem na vida de sua comunidade, sendo este de grande significação por ser não apenas uma atividade física, mas algo que promove também a capacidade de um desprender-se de amarras, por exemplo, na consideração do corpo e das suas possibilidades.

Logo após, a professora expande a noção do "libertar-se", indicando que esta está relacionada aos aprendizados que o pole dance possibilita aos seus praticantes. Nos trechos, existe muita a questão de você (.) aprender a lidar com o seu próprio corpo (linhas 28 e 29) e pra você aprender a se olhar e a ver o que você é capaz de fazer (linhas 36 a 38), tais aprendizados têm significado avaliativo positivo do pole como libertação, representando características benéficas que o constituem. Cabe ressaltar os sentidos criados pela escolha léxico-gramatical do verbo "aprender", quando podemos inferir que a praticante vai desenvolvendo as ações descritas, ao longo da prática do pole dance, em um processo gradativo.

No primeiro caso (linha 29), as praticantes (representadas por "você") vão aderindo a uma nova forma de lidar com o seu corpo, que possibilita ir se sentindo confortável com ele de "top e short" (linha 33), o que inferimos ser um afeto de segurança institucionalizado no julgamento positivo de estima social, relativo à 
possível nova atitude causada pela atividade. No segundo trecho (linha 37), também temos a ocorrência de uma avaliação por julgamento positivo, quando Marina sinaliza que a mudança gradativa do olhar vai se dando a partir do reconhecimento das pole dancers acerca da capacidade de realizarem certos movimentos com o seu corpo, movimentos que poderiam antes considerar impossíveis (linhas 36 a 39). Nesse momento, também vemos o refletir de um afeto de segurança das praticantes ao se sentirem confiantes no reconhecimento de suas competências, o que nos leva a considerar que a professora demonstra entender o "aprender" como um processo de transformação, física e emocional, carregado de afeto.

Marina escolhe o atributo "seminua" em referência à seminudez que é constitutiva do pole dance, quando faz avaliações positivas do termo, contrariando sua acepção estigmatizada: algo depreciativo, vulgar e calcado em exposição extrema e/ou indevida. Para a professora, a seminudez é vital para prática do pole dance e é através da vivência com o seu corpo seminu que as pole dancers vão aprendendo a lidar com ele, como que em um ato de aceitação desse corpo (linhas 30 a 35). Além disso, nas linhas 37 a 39, tal seminudez é ressignificada como potência, uma vez que é estando seminua que a praticante é capaz de fazer o que faz. Sendo assim, a seminudez ganha agência e extrema relevância para a atividade em um ato de resistência ao seu estigma, feito pela professora, o que nos leva ao entendimento de que o comportamento desviante (GOFFMAN, [1963] 1988) da seminudez é por ela considerado uma atitude normal no contexto em tela.

No excerto 2, a seguir, Marina desenvolve suas considerações sobre o fazer do pole dance, enfatizando as questões relacionadas ao corpo. 
Excerto 2

\begin{tabular}{|c|c|c|}
\hline $\begin{array}{l}83 \\
84\end{array}$ & Marina & $\begin{array}{l}\text { hoje em dia eu diria } 998 \text { thh feminino (.) então } \\
\text { você tá (.) com mulheres num ambiente seguro }\end{array}$ \\
\hline 85 & & porque é um ambiente (.) para mulheres feitos por- \\
\hline 86 & & feito por mulheres \\
\hline 87 & Lorena & uhum \\
\hline 88 & Marina & em que você (.) trabalha o seu corpo e o corpo de \\
\hline 89 & & outras mulheres e então >existe essa coisa< do do \\
\hline 90 & & você não ser julgada dentro de uma aula de pole \\
\hline 91 & & >independente de cê ser< gorda magra bonita é: : \\
\hline 92 & & dentro de um padrão fora de um padrão você aprende \\
\hline 93 & & a olhar que existem vários (.) e inúmeros padrões \\
\hline 94 & & $>$ vamos dizer assim $<=$ \\
\hline 95 & Lorena & $=$ entendi \\
\hline 96 & Marina & existem milhares de corp-milhares de tipos de \\
\hline 97 & & corpos e >existe essa coisa de você< (.) ver que \\
\hline 98 & & não existe um corpo perfeito porque tem a a $a$ \\
\hline 99 & & mulher que chega (.) magra maravilhosa nananan ela \\
\hline 100 & & entra numa sala ela se olha >seminua na frente de \\
\hline 101 & & um espelho< e fala pu: :tz >isso aqui podia tá \\
\hline 102 & & melhor isso aqui podia não tá melhor ai essa \\
\hline 103 & & barriga ai essa bunda ai esse [peito] \\
\hline 104 & Lorena & [sim] \\
\hline 105 & Marina & [que não sei que]< \\
\hline 106 & & e eu sempre falo-e você olha pra aquela mulher que \\
\hline 107 & & você julgava perfeita e ela tá (.) se depreciando \\
\hline 108 & & na frente de um espelho sabe? \\
\hline $\begin{array}{l}109 \\
110\end{array}$ & $\begin{array}{l}\text { Lorena } \\
\text { Marina }\end{array}$ & $\begin{array}{r}\operatorname{sim}(.) \text { cê fica muito [exposto né?] } \\
\qquad>[\text { e cê fica com }]<\text { você tá }\end{array}$ \\
\hline 111 & & muito exposto então você aprende a lidar com essa \\
\hline 112 & & osição toda \\
\hline 113 & Lorena & \\
\hline 114 & Marina & =e aprende a gostar dessa exposição toda \\
\hline 115 & Lorena & \\
\hline
\end{tabular}

Marina dá continuidade ao explorar das características que seriam constitutivas do pole dance, com instanciações avaliativas de julgamento positivo de estima social, que são reforçadas pelo uso de "existir" (linhas 89, 93, 96 a 98) relacionado à forma como as praticantes lidam com o corpo. A escolha pelo verbo "existir" nos leva a interpretar as avaliações da professora como sendo fatos recorrentes, conferindo as mesmas um alto grau de força gradativa. Observamos, nas linhas 89 e 90, por exemplo, que ao mencionar que >existe essa coisa< do do você não ser julgada dentro de uma aula de pole há a construção de que essa boa atitude é algo esperado e comum no meio. Além disso, o fato de a praticante não ser julgada pelos seus pares, e nem se autojulgar, também está relacionado ao aprendizado de entender que há vários e inúmeros padrões corporais (linha 93). No caso, o aprendizado tem um sentido processual, que vai construindo 
uma transformação desse olhar da praticante (referenciada pelo uso de "você", nas linhas 92 e 93), que poderá se livrar das amarras do pensamento hegemônico, acerca da existência de um corpo "padrão" a ser almejado, aprendendo, assim, a ver que não existe um corpo perfeito (linhas 97 e 98).

Nesse caso, vemos emergir no discurso de Marina uma problematização sobre a estigmatização do corpo considerado "fora do padrão" pela/na sociedade em geral. A ideia de que o padrão de beleza para um corpo feminino é geralmente considerado o do tipo físico magro e curvilíneo, ilustra o que Fairclough (1997, 2001) entende como um pensamento hegemônico. No caso, a naturalização desse discurso faz com que outras formas corporais, as que não se encaixam nesse padrão, sejam depreciadas de alguma maneira e alvo de preconceitos e, com isso, marginalizadas e estigmatizadas (MOITA LOPES et al. 2006; GOFFMAN, [1963]. Não só em relação ao "ser belo", mas o ideal do corpo magro acaba também se difundindo como o "corpo necessário" para prática de certas atividades, o que pode fazer com que muitas mulheres interessadas pelo pole dance acabem desistindo de praticá-lo, por achar que seus corpos são inadequados para a atividade, "um corpo que não cabe ali". Mesmo a mulher que decide ingressar no universo do pole dance, ao menos no início da sua prática, pode estar influenciada pelo pensamento da "imperfeição" e "inadequação" do seu corpo, no que se refere à questão da sua estética e/ou capacidade, possibilitando que encontre dificuldades em lidar com a sua exposição (HOLLAND, 2010; ALLEN, 2011).

Além disso, para corroborar a ideia de que não existe um corpo perfeito (linha 98), Marina traz o exemplo da mulher que mesmo magra - tido como o padrão de beleza já alcançado - se mostra insatisfeita com vários aspectos (linhas 98 a 105). Quando Marina diz porque tem a a a mulher que chega (.) magra maravilhosa nananan (linhas 98 e 99), sua avaliação traduz-se na esfera estética por uma apreciação positiva de reação - um corpo que agrada por ser bonito - ou até de impacto - ele chama a atenção por ser atraente - o que acreditamos ser a reprodução de um pensamento hegemônico sobre a mulher magra: aquilo que é belo e ideal. Apesar de essa apreciação se expandir no trecho você olha pra aquela mulher que você julgava perfeita (linhas 106 e 107), ela é contraposta à atitude desta mulher de autodepreciar-se (linhas 107 e 108), um comportamento entendido aqui como avaliado negativamente por Marina, no âmbito da estima social por não-normalidade. Isso quer dizer que é uma atitude estranha, que não se esperava ser comum de uma mulher que se encaixa no padrão. 
Interpretamos, a partir dessas colocações de Marina, que estamos diante de uma situação complexa onde o discurso hegemônico parece entranhar-se em todas nós (os usos do "você" inclui a ela e a outras mulheres) de alguma maneira e nos influenciar negativamente. Por exemplo, a busca eterna por um corpo "perfeito", sempre inatingível, e acreditar que o que temos não está bom o suficiente, pode dificultar que qualquer uma de nós reconheça o seu corpo como belo, potente, legítimo e válido. Toda essa problemática vem à tona para as pole dancers no momento em que se encontram completamente expostas nas aulas, como Lorena diz à Marina (linha 109), em uma exposição não só dos corpos em si, mas também de como estes são avaliados. É aqui que entra o aprendizado desenvolvido durante a prática da atividade, enfatizado por Marina desde o início da conversa: você aprende a lidar com o corpo, você aprende a lidar com essa exposição toda (linhas 111 e 112), o que indica a construção discursiva de um afeto de segurança (a confiança que você cria). A pole dancer aprende não só a lidar, como também aprende a gostar dessa exposição toda (linha 114), manifestando, no campo do afeto de satisfação, o prazer por essa exibição.

Pelas considerações de Marina, é possível entendermos que o pole dance pode atuar como a quebra do estigma do corpo "inadequado", "não belo", estigmatizado como defeituoso e em desvantagem (GOFFMAN [1963] 1988), uma vez que é por meio dos aprendizados desenvolvidos durante a prática que a problematização do estigma pode ocorrer. Dessa maneira, a prática do pole dance possibilita promover, ao mesmo tempo, a libertação do corpo e a abertura de um olhar mais inclusivo: um espaço para a dissolução de barreiras e de pensamentos limitadores e para a afirmação da noção de que todos os corpos são válidos.

Chegamos ao momento da conversa em que Marina responde a uma pergunta feita por sua interlocutora, cujo tema volta-se a preconceitos e estereótipos em relação ao pole dance, avaliados negativamente por Lorena, como o lado negativo (linha 128) da prática da modalidade. Isto será discutido nos excertos 3,4 e 5 , a seguir. 
Excerto 3

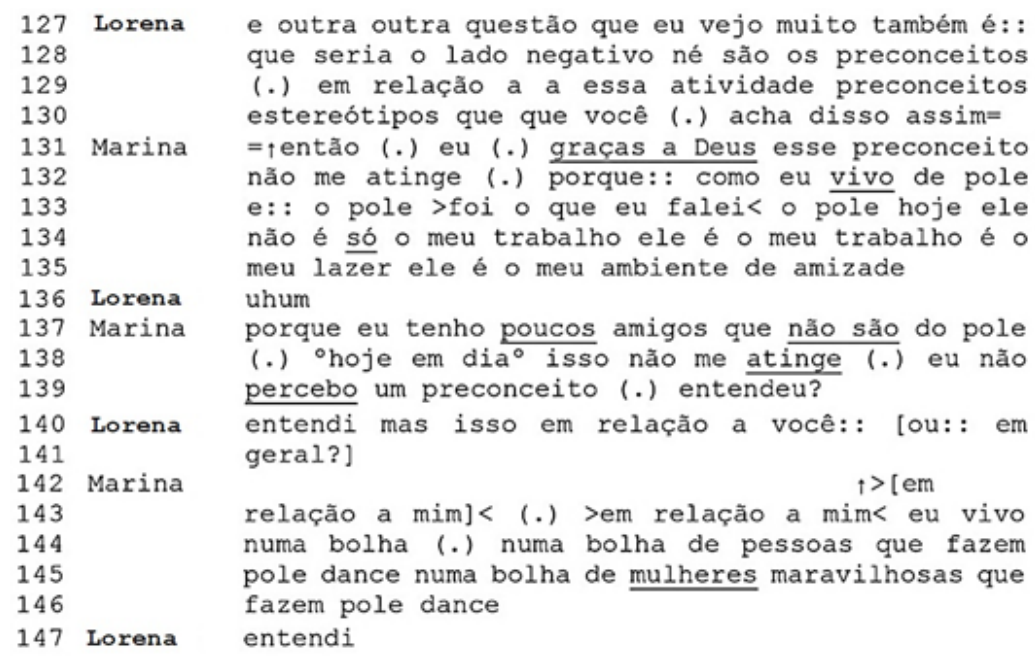

Marina diz não perceber (linhas 138 e 139) um preconceito em relação à sua figura por ela viver de pole dance (para trabalho, lazer, amizade - linhas 133 a 135) e viver numa bolha de seus praticantes, conforme exposto nas linhas 143 a 146. Em nossa interpretação, a professora avalia sua inserção na atividade em questão a partir da produção de um afeto positivo de satisfação, construído em sua fala graças a Deus esse preconceito não me atinge (linhas 131 e 132), especialmente em "graças a Deus", graduado com voz mais alta. Notamos, ainda, que Marina reconhece que há preconceitos, mas que "esse preconceito" não a atinge. A escolha do pronome demonstrativo "esse" localiza o preconceito que não a afeta, fazendo com que ela se afaste do mesmo, inclusive, por viver em uma bolha, o que cria, por meio do afeto positivo de segurança, o forte sentido de proteção, de escudo, e não contato direto com a realidade que Lorena traz para problematização.

Contudo, logo em seguida, Marina narra uma situação de preconceito em relação a um festival de pole dance, que observamos atingi-la não só indiretamente - por ter sido uma discriminação com um evento da comunidade de prática na qual ela se insere - como também diretamente - por ter sido ela uma das organizadoras do festival e uma das pole dancers que se apresentaram nele. 
Excerto 4

\begin{tabular}{|c|c|c|}
\hline 148 & Marina & então assim (.) eu não percebo um preconceito (.) \\
\hline 149 & & ma:s se você for pensar (.) a gente produz o \\
\hline 150 & & Festival de Pole [né?] \\
\hline 151 & Lorena & {$[\mathrm{sim}]$} \\
\hline 152 & Marina & e: : esse ano a gente resolveu faze: : r u-um um dia \\
\hline 153 & & com um ensaio aberto com uma bilheteria (.) sem \\
\hline 154 & & cobrar e a gente convidou (.) várias organizações \\
\hline 155 & & sociais que trabalham com dança $=$ \\
\hline 156 & Lorena & $=\mathrm{sim}$ \\
\hline 157 & Marina & $>$ e a gente recebeu< mu: ito mui-uma resposta \\
\hline 158 & & muito negativa da maioria delas [porque]= \\
\hline 159 & Lorena & {$[$ sim $]$} \\
\hline 160 & Marina & $=[$ dentro $]$ do meio \\
\hline 161 & & da dança eles não consideram o pole (.) uma tdança \\
\hline 162 & & eles acham vulgar eles acham é: : (.) que não é \\
\hline 163 & & uma dança \\
\hline 164 & Lorena & entendi \\
\hline 165 & Marina & [entendeu?] \\
\hline 166 & Lorena & [sim] \\
\hline
\end{tabular}

Neste excerto, Marina começa avaliando a resposta que recebeu das organizações sociais de dança (doravante, OSDs) como nada acolhedora, altamente graduada como "muito negativa" (linhas 157 e 158), construída no campo do afeto por insatisfação - as produtoras-pole dancers não gostaram da resposta. Em sequência, especula sobre qual seria o pensamento das OSDs que motivou o retorno dado, ao ponderar que eles não consideram o pole (.) uma dança eles acham vulgar eles acham é:: (.) que não é uma dança (linhas 161 e 162). Aqui, é oportuno retomar o nosso entendimento de que não podemos separar o indivíduo de suas práticas sociais (MOITA LOPES, 2006 et al.; RAJAGOPALAN, 2006). Portanto, salientamos a estreita relação entre a atividade e suas praticantes: se o pole dance é vulgar, então as praticantes também o são, reforçando, a partir de um julgamento negativo de estima social, a ideia de que o seu comportamento está fora do esperado e do não aceito pela sociedade, considerado anormal e desviante.

No próximo fragmento, a participante continua a comentar sobre a resposta, trazendo a fala reportada das OSDs. 
Excerto 5

\begin{tabular}{|c|c|c|}
\hline 67 & Marina & e: : che-a gente chegou a ter uma resposta (.) da \\
\hline 168 & & seguinte forma (.) "eu acho pole dance legal mas \\
\hline 169 & & como que eu explicaria pros PAIS das crianças que \\
\hline 170 & & fazem aula aqui que eu vou levar elas num \\
\hline 171 & & espetáculo de pole dance?" >mas isso é porque as \\
\hline 172 & & pessoas não sabem $\circ$ que é $\circ$ pole dance $<\circ$ pole \\
\hline 173 & & pode ser sensual? pode e deve se quiser \\
\hline 174 & Lorena & \\
\hline 175 & Marina & mas como ele pode ser milhões de outras coisas \\
\hline 176 & & sabe? \\
\hline 177 & Lorena & pode ser mais acrolbá::tico né \\
\hline 178 & Marina & [ele pode ser mais [acrobático \\
\hline 179 & Lorena & [mais \\
\hline 180 & & artistico \\
\hline 181 & Marina & [ele \\
\hline 182 & & ser artísticol ele pode ser (.) contemporâneo ele \\
\hline 183 & & pode ser só dançado sen acroba-sem acrobacia ele \\
\hline 184 & & pode ser (.) só acrobacia então assim \\
\hline 185 & Lorena & ${ }^{\circ}$ muito variado $\left[\right.$ né?] ${ }^{\circ}$ \\
\hline 186 & Marina & $>$ [ele é] muito variado e existe \\
\hline 187 & & (.) essa coisa (.) das pessoas não saberem $\circ$ que \\
\hline 188 & & que é pole (.) então a gente ficou mui-bem \\
\hline 189 & & chateado quando o ensaio aberto não deu (.) a \\
\hline 190 & & $\overline{\text { procura que a gente queria que desse }}$ \\
\hline 191 & Lorena & {$[\mathrm{sim}]$} \\
\hline 192 & Marina & [entendeu?] \\
\hline 193 & Lorena & [imagino] \\
\hline 194 & Marina & [por preconceito] de pessoas que NÃo (.) sabem o \\
\hline 195 & & que que é pole >porque se cê pegar< (.) um \\
\hline 196 & & espetáculo de pole a pe-as pessoas que assistem \\
\hline 197 & & são pessoas do meio \\
\hline 198 & Lorena & \\
\hline
\end{tabular}

Logo no início deste último excerto, nas linhas 167 e 168, a professora, dando sequência à sua avaliação da resposta recebida, anuncia que trará a fala reportada de uma OSD, ao dizer a gente chegou a ter uma resposta (.) da seguinte forma. Analisamos que a introdução da fala reportada, especialmente pela escolha da expressão "da seguinte forma", antecipa a carga avaliativa de reprovação do retorno dado, por intermédio de um julgamento negativo de estima social, uma vez que se relaciona à sua fala anterior, apresentada e comentada no excerto 4, nas linhas 157 a 163.

Entendemos que todas as recusas recebidas da maioria das OSDs convidadas foram sintetizadas nas avaliações presentes na fala que Marina diz ser de uma dessas organizações. A justificativa fornecida se caracteriza como uma avaliação implícita, uma vez que o sentido negativo é construído por meio da pergunta retórica: "mas 
como que eu explicaria pros PAIS das crianças que fazem aula aqui que eu vou levar elas num espetáculo de pole dance?" (linhas 168 a 171). Inferimos que há aqui a reprodução de um macrodiscurso hegemônico e conservador do pole dance como desviante da normalidade, nos termos de Goffman ([1963] 1988), e que reforça estereótipos acerca da atividade. Tal julgamento negativo de estima social, no domínio da nãonormalidade, demonstra a impossibilidade de explicar-se aos pais o contato de seus filhos com o pole dance. Subentendemos pelo posicionamento das OSDs que os pais compartilhariam de sua perspectiva - ou seja, avaliariam da mesma forma negativa - e que provavelmente reprovariam e não permitiram a ida de seus filhos ao espetáculo. Fica muito evidente, nesse momento discursivo, o descrédito (GOFFMAN, [1963] 1988) atribuído ao pole dance, a partir de sua estigmatização como inapropriado, de má qualidade, vulgar (excerto 4, linhas 160 a 163), o configurando como inabilitado para aceitação social plena (GOFFMAN, [1963] 1988).

A concepção negativa compartilhada por essas organizações sociais, por muitos pais e pela parcela conservadora da sociedade é avaliada explicitamente por Marina como preconceito (linhas 194 e 195), consequência do desconhecimento sobre o que o pole dance possa ser. A professora frisa tal falta de conhecimento ao repetir três vezes que as pessoas não sabem o que é o pole dance (linhas 171 e 172, 187 e 188, 194 e 195), o que analisamos como um julgamento negativo no âmbito da estima social por capacidade - as pessoas parecem ser incapazes de buscar informações e se esclarecerem acerca da prática da modalidade, o que gera os estigmas construídos nas avaliações preconceituosas sobre a atividade.

Diante desse contexto, Marina e Lorena, em falas que consideramos atos discursivos de resistência e com um potencial para uma desconstrução de estigmas, criticam o descrédito aferido à modalidade. Ao ressaltar que o pole pode ser sensual? pode e deve se quiser (linhas 172 e 173), a professora cria uma visão que legitima e reconhece o espaço da vertente sensual e que desafia qualquer posicionamento preconceituoso. No entanto, no decorrer da interlocução, as participantes também exploram a existência de outros enfoques nas performances, como a execução de acrobacias, o conceito artístico, as danças contemporâneas, dentre outros aspectos, mostrando que o pole dance é muito variado e democrático (linhas 175 a 186).

Todas essas rotulações negativas realizadas pelas OSDs, e que deixam claro a divergência de pensamento entre pole dancers e um público leigo, fez com que o 
ensaio aberto do Festival de Pole sofresse consequências que abalaram diretamente as produtoras do evento, como observamos na fala de Marina, quando diz então a gente ficou mui-bem chateado quando o ensaio aberto não deu (.) a procura que a gente queria que desse (linhas 188 a 190). A partir da construção de um afeto explícito de insatisfação e de infelicidade (expresso pelo uso de mui-bem chateado, com gradação em "bem" e "chateado") - referentes à frustração e ao desagrado com a pouca visibilidade que o ensaio teve - percebemos no discurso da professora, em nível microdiscursivo, não apenas esse descontentamento pontual, bem como conexões com a ordem macrossocial discursiva, na qual os estigmas acarretam a não legitimação da atividade.

\section{CONSIDERAÇÕES FINAIS}

A reflexão desenvolvida na investigação dos dados possibilitou ouvirmos as vozes de duas pole dancers, no que diz respeito aos estigmas e preconceitos relacionados à atividade que praticam. O foco das análises concentrou-se no discurso de Marina, que explorou diversos pontos voltados aos discursos hegemônicos (FAIRCLOUGH, 1997, 2001) sobre o pole dance, quando nos foi possível observar que as suas avaliações problematizaram os sentidos que o estigmatizam (GOFFMAN, [1963] 1988, [1964] 1998).

Em nossas interpretações, apontamos que as avaliações da professora foram direcionadas a estigmas sobre a seminudez, ao corpo ideal $v$ s. corpo fora do padrão e ao fazer do pole dance em si. As avaliações construíram-se, principalmente, nos campos semânticos do afeto e do julgamento, bem como em algumas instâncias de apreciação, estabelecendo o contraste entre os posicionamentos da comunidade do pole dance e do público leigo, em especial, o que critica a prática da atividade, a exemplo das organizações sociais de dança referidas por Marina.

As avaliações negativas da professora voltaram-se aos discursos hegemônicos que conferem descrédito à atividade e que marginalizam as praticantes, uma vez que são tidas como vulgares e rotuladas como desviantes e anormais. Por outro lado, suas avaliações positivas caracterizaram o seu entendimento da dança-esporte que pratica como uma atividade que proporciona autodescoberta, aceitação, empoderamento, libertação e muitos aprendizados. Por meio das críticas realizadas, seja por suas avaliações positivas do pole dance ou por suas avaliações negativas da

9. Nome fictício. 
postura adotada pelos que não conhecem a atividade, Marina cria um discurso de resistência aos estigmas emergentes na interação com a Lorena.

A discussão proposta nos leva a considerar que os preconceitos sofridos pelo pole dance - a exemplo de sua inferiorização como dança para alguns profissionais desse meio, da sua não validação e não legitimação pelas falas externas enquanto atividade "digna de ser feita", dentre outros aspectos - podem impossibilitar a sua maior visibilidade, assim como atrair mais pessoas para suas salas de aula, festivais e campeonatos.

Sendo assim, acreditamos que esta pesquisa é uma forma de criar inteligibilidades sobre a prática do pole dance, a partir do entendimento do que ele seja, uma noção coerente com a realidade, por ser pautada na vivência e nas vozes de quem está "de dentro". Conforme discutido ao longo do trabalho, ao nos alinharmos a essas vozes propomos uma desaprendizagem (FABRICIO, 2006) dos posicionamentos que marginalizam o universo do pole dance, desafiando-os, uma vez que os compreendemos como não-éticos, por serem produtores de violência simbólica e que, portanto, fazem mal à sua comunidade.

\section{REFERÊNCIAS}

ALLEN, K. L. (2011). Poles apart?: women negotiating feminity and feminism in the fitness pole dancing class. 2011. Tese (Doutorado em Filosofia). University of Nottingham, Nottingham.

BIAR, L. de A. (2012). "Realmente as autoridades veio a me transformar nisso": Narrativas de adesão ao tráfico e a construção discursiva do desvio. 2012. Tese (Doutorado em Letras) - Programa de Pós-Graduação Estudos da Linguagem, Pontifícia Universidade Católica do Rio de Janeiro, Rio de Janeiro.

BUTLER,J. (1988). Performative Acts and Gender Constitution: An Essay in Phenomenology and Feminist Theory. Theatre Journal, Baltimore, v. 40, n. 4, pp. 519-531.

BUTLER, J. (1990). Gender trouble: feminism and the subversion of identity. New York: Routledge.

COLLINS, P. H. (2017). Se perdeu na tradução? Feminismo negro, interseccionalidade e política emancipatória. Revista Parágrafo, São Paulo, v. 5, n. 1, pp. 6-17.

DENZIN, N. K.; LINCOLN, Y. S. (2006). Introdução: a disciplina e a prática da pesquisa qualitativa. In: DENZIN, N. K.; LINCOLN, Y. S. (Orgs.). O planejamento da pesquisa qualitativa: teorias e abordagens. Porto Alegre: Artmed. pp. 15-42. 
ESPAÇO ALFA. (2014). História do Pole Dance. Disponível em: < http://espacoalfa.com.br/ novo/? page_id=9525>. Acesso em: 30 de junho de 2019.

FABRÍCIO, B. F. (2006). Linguística aplicada como espaço de "desaprendizagem": redescrições em curso. In: MOITA LOPES, L. P. (Org.). Por uma linguística aplicada indisciplinar. São Paulo: Parábola. pp. 45-65.

FAIRCLOUGH, N. (1997). Discurso, mudança e hegemonia. In: PEDRO, Emília R. (Org.). Análise Crítica do Discurso: uma perspectiva sócio-política e funcional. Lisboa: Editorial Caminho. pp. 77-104.

FAIRCLOUGH, N. (2001). Discurso e mudança social. Brasília: Editora UnB.

FERREIRA, C. F. (2015). Redescobrindo ser-si-mesmo: a existencialidade de mulberes praticantes de pole dance Dissertação de Mestrado. Programa de Pós-Graduação em Psicologia. Universidade Federal do Amazonas, Manaus.

GOFFMAN, E. ([1963] 1988). Estigma - Notas sobre a manipulação da identidade deteriorada. Rio de Janeiro: Zahar.

GOFFMAN, E. ([1964] 1998). A situação negligenciada. In: RIBEIRO, B. T.; GARCEZ, P. M. (Orgs.). Sociolinguística interacional. Porto Alegre: Age, pp. 11-15.

GONÇALVES, A. C. (2017). "Viva o matriarcado pole dance": uma etnografia das relações entre corpo, gênero e cidade na prática do pole dance. 2017. Monografia (Graduação em Antropologia) Universidade Federal Fluminense, Niterói.

HALLIDAY, M. A. K.; MATTHIESSEN, C. (2014). Halliday's introduction to functional grammar. London e New York: Routledge.

HOLLAND, S. (2010). Pole Dancing, Empowerment and Embodiment. New York: Palgrave Macmillan.

HOOKS, b. (1982). Ain't I a woman? London: Pluto Press.

HOOKS, b. (1984). Feminist Theory from margin to center. Boston: South End Press.

HUNSTON, S.; THOMPSON, G. (2000). (Eds.). Evaluation in Text: Authorial stance and the construction of discourses. Oxford: Oxford University Press.

LEAL E SILVA, I. (2014). Corporalidade no pole dance: uma análise antropológica. 29a Reunião Brasileira de Antropologia, 03 e 06 de agosto de 2014, Natal/RN. 
LODER, L. L.; JUNG, N. M. (Orgs.). (2009). Análises de fala-em-interação institucional: a perspectiva da Análise da Conversa Etnometodológica. Campinas: Mercado de Letras.

MARTIN, J. R. (2000). Beyond exchange: appraisal systems in English. In: HUNSTON, S.; THOMPSON, G. (Eds.). Evaluation in Text: Authorial Stance and the Construction of Discourse. New York: Oxford University Press, pp. 142-175.

MARTIN, J. R.; WHITE, P. R. R (2005). The Language of Evaluation: Appraisal in English. New York: Palgrave/ Macmillan.

MARTIN, J. R.; ROSE, D. (2007). Working with Discourse: meaning beyond the clause. $2^{\text {a }}$ ed. New York: Continuum.

MEEPOS, D. (2012). The Purgatory of Pole Dancing. UCLA Women's Law Journal, Los Angeles, v. 19, n. 2, pp. 214-259.

MICHAELIS DICIONÁRIO BRASILEIRO DA LÍNGUA PORTUGUESA (2020). Disponível em: < michaelis.uol.com.br/moderno-portugues/ > Acesso em: 27 de outubro de 2020 .

MIGNOLO, W. D. (2000). Local Histories/Global Designs: Coloniality, Subaltern Knowledges, and Border Thinking. Princeton University Press.

MISHLER, E. G. (1986). The Analysis of Interview-Narratives. In: SARBIN, T. R. (Ed.). Narrative Psychology: The Storied Nature of Human Conduct. New York: Praeger, pp. 233-255.

MOITA LOPES, L. P. (2002). Identidades fragmentadas. São Paulo: Mercado das Letras.

MOITA LOPES, L. P. (2006). (Org.). Por uma linguística aplicada indisciplinar. São Paulo: Parábola.

MOITA LOPES, L. P. (2006). Linguística aplicada e vida contemporânea: problematização dos construtos que têm orientado a pesquisa. In: MOITA LOPES, L. P. (Org.). Por uma linguística aplicada indisciplinar. São Paulo: Parábola. pp. 85-107.

MOITA LOPES, L. P. (2006). Uma linguística aplicada mestiça e ideológica: interrogando o campo como linguista aplicado (Introdução). In: MOITA LOPES, L. P. (Org.) Por uma linguística aplicada indisciplinar. São Paulo: Parábola. pp.13-44.

MOITA LOPES, L. P. (2013). (Org.). Linguística Aplicada na modernidade recente - Festschrift para Antonieta Celani. São Paulo: Parábola. 
NÓBREGA, A. N. (2009). Narrativas e avaliação no processo de construção do conbecimento pedagógico: abordagem sociocultural e sociossemiótica. Tese (Doutorado em Letras) - Programa de Pós-Graduação Estudos da Linguagem, Pontifícia Universidade Católica do Rio de Janeiro, Rio de Janeiro.

OLVIEIRA, A. K. S. (2016). Pole dance: contextos e aproximações com os estudos de Rudolf Laban. Trabalho de conclusão de curso. Licenciatura plena em dança. Universidade Federal do Rio Grande do Norte, Natal.

PENNYCOOK, A. (2006). Uma linguística aplicada transgressiva. In: MOITA LOPES, L. P. (Org.) Por uma linguística aplicada indisciplinar. São Paulo: Parábola. pp. 67-84.

RAJAGOPALAN, K. (2003). Por uma lingüística crítica: linguagem, identidade e questão ética. São Paulo: Parábola Editorial.

RAJAGOPALAN, K. (2006). Repensar o papel da linguística aplicada. In: MOITA LOPES, L.P. (Org.). Por uma linguística aplicada indisciplinar. São Paulo: Parábola. pp. 149-168.

REZENDE, C. B.; COELHO, M. C. (2010). Antropologia das Emocõos. Rio de Janeiro: FGV.

SACKS, H., SCHEGLOFF, E. A.; JEFFERSON, G. (1974). A simplest systematic for the organization of turn-taking for conversation. Language, Baltimore, v. 50, n. 4, pp. 696-735.

SANTOS, R. O. (2018). Pole Dance: Dança on Esporte? Trabalho de conclusão de curso. Bacharel em Educação Física. Universidade Federal do Rio Grande do Norte, Natal.

THOMPSON, G; ALBA-JUEZ, L. (2014). (Eds.). Evaluation in Context. Philadelphia: John Benjamin.

VIAN JR., O. (2010). O Sistema de Avaliatividade e a linguagem da avaliação. In: VIAN JR., O. et al. (Orgs.) A linguagem da avaliação em língua portuguesa: estudos sistêmicofuncionais com base no Sistema de Avaliatividade. São Carlos: Pedro \& João Editores. pp. 19-29.

VIAN JR., O. (2013). Linguística sistêmico-funcional, linguística aplicada e linguística educacional. In: MOITA LOPES, L. P. (Org.) Linguística Aplicada na modernidade recente - Festschrift para Antonieta Celani. São Paulo: Parábola. pp. 123-141.

WHITEHEAD, K.; KURZ, T. (2009). "Empowerment" and the Pole: A Discursive Investigation of the Reinvention of Pole Dancing as a Recreational Activity. Feminism \& Psychology, Exeter, v. 19, n. 2, pp. 224-244. 


\section{ANEXO}

Convenções de Transcrição (SACKS; SCHEGLOFF; JEFFERSON, 1974; LODER; JUNG, 2009)

\begin{tabular}{|c|c|c|c|}
\hline \multicolumn{4}{|c|}{ Aspectos da produção da fala } \\
\hline . & Entonação descendente & $\uparrow$ & $\begin{array}{l}\text { Som mais agudo do que os do } \\
\text { entorno }\end{array}$ \\
\hline$?$ & Entonação ascendente & $\downarrow$ & $\begin{array}{l}\text { Som mais grave do que os do } \\
\text { entorno }\end{array}$ \\
\hline , & $\begin{array}{l}\text { Entonação intermediária, de } \\
\text { continuidade }\end{array}$ & $\mathrm{Hh}$ & Aspiração ou riso \\
\hline- & Parada súbita & .hh & Inspiração audível \\
\hline$\underline{\text { Sublinhado }}$ & Ênfase em som & opalavra॰ & Fala em voz baixa \\
\hline MAIÚSCULA & Fala em voz alta ou muita ênfase & $>$ palavra $<$ & Fala mais rápida \\
\hline : ou $::$ & Alongamentos & $<$ palavra $>$ & Fala mais lenta \\
\hline [ ] & Fala sobreposta & \multicolumn{2}{|c|}{ Formatação, comentários, dúvidas } \\
\hline & Tempo & $=$ & $\begin{array}{c}\text { Elocuções contíguas, } \\
\text { enunciadas sem pausa entre } \\
\text { elas }\end{array}$ \\
\hline$\ldots$ & Pausa não medida & $($ ) & Fala não compreendida \\
\hline$(2.3)$ & Pausa medida & (palavra) & Fala duvidosa \\
\hline (.) & $\begin{array}{c}\text { Pausa de menos de } 2 \text { décimos } \\
\text { de segundo }\end{array}$ & $((\quad))$ & $\begin{array}{l}\text { Comentário do analista, } \\
\text { descrição de atividade não } \\
\text { vocal }\end{array}$ \\
\hline \multicolumn{4}{|c|}{ Outros } \\
\hline & "palavra" & & Fala relatada \\
\hline
\end{tabular}

Recebido: 14/7/2020

Aceito: 6/11/2020

Publicado: 11/11/2020 